\title{
Estratégias de Ensino para a Aprendizagem do Cálculo Diferencial e Integral
}

\author{
Lecir Dorneles Cláudia Piva A. Patricia Spilimbergo \\ Depto de Ciências Exatas e Engenharias, DCEEng, UNIJUÍ \\ 98700-000, Ijuí, RS \\ E-mail: lecird@unijui.edu.br; cpivaa@gmail.com; patspi@unijui.edu.br
}

\section{RESUMO}

As dificuldades que os alunos apresentam ao ingressar em um curso superior, no que se refere à aprendizagem dos conteúdos desenvolvidos nas disciplinas da área de matemática, tem sido uma constante preocupação em nossa prática.

O processo de ensino aprendizagem é complexo, passa pelo professor, com suas metodologias na maioria das vezes já desgastadas, envolve um aluno desmotivado ou sem tempo para estudar. Além disso, não são poucas as vezes que contamos com um grande número de alunos em cada turma, o que vem dificultar ainda mais a aprendizagem. Diante deste cenário e dos resultados no final de cada semestre nos inquietamos e refletimos sobre as ações realizadas e isto nos instigou e nos levou a buscarmos alternativas que pudessem vislumbrar alguma melhoria.

Encontramos muitos artigos que tratam deste problema, por exemplo, no Congresso Brasileiro de Ensino de Engenharia (COBENGE) [2], muitos autores, relatam em seus artigos, algumas possibilidades de trabalho em sala de aula ou outras estratégias para buscar sanar as dificuldades dos alunos bem como propiciar um bom rendimento nas disciplinas de Cálculo. Podemos citar [1] que nos diz: "Muitos alunos, no entanto, iniciam tais disciplinas sem terem desenvolvido estruturas cognitivas relacionadas à interpretação da linguagem matemática... Revelam, assim, dificuldades em habilidades de reflexão, exploração e dedução. Às vezes, guardam a técnica e não o significado dos conceitos. E, consequentemente, apresentam dificuldades no desempenho acadêmico".

Frente a essa realidade, um grupo de professoras da área de Matemática do Departamento de Ciências Exatas e Engenharias (DCEEng) da UNIJUÍ constituiu um projeto de pesquisa visando investigar e propor estratégias de ensino no sentido de buscar uma efetiva aprendizagem dos alunos nas disciplinas de Cálculo. Assim, este trabalho tem por objetivo relatar alguns resultados dessa pesquisa.

Nos cursos de Engenharias de nossa Universidade temos uma diversidade de alunos, os quais concluíram seu ensino médio em diferentes modalidades, como por exemplo, escola regular, ensino supletivo, entre outros, bem como alunos que não trabalham e apenas estudam, aqueles que não se dedicam suficientemente ao estudo, e ainda aqueles que não têm tempo para estudar. Além disso, o grande índice de reprovações nas disciplinas iniciais de Matemática (Cálculo I e Geometria Analítica e Vetores) desses cursos impacta de forma significativa na continuidade do curso em função dos pré-requisitos atrelados a elas.

Considerando esta realidade realizamos algumas ações no sentido de retomar conceitos de Matemática Básica, necessários para a compreensão e o acompanhamento satisfatório nas disciplinas iniciais de Matemática destes cursos. Entre elas, a criação de um Curso de Nivelamento on-line que aconteceu no primeiro semestre de 2010. A análise dos resultados desta ação gerou nos colegiados dos cursos de Engenharias, como também nos colegiados de Matemática e Ciência da Computação, discussões sobre a necessidade da incorporação nas grades curriculares destes cursos de uma disciplina presencial que abordasse os assuntos trabalhados e explorados neste curso de nivelamento. Assim, no ano de 2013, foi criada a disciplina de Pré-Cálculo nos currículos dos cursos de graduação do DCEEng da nossa instituição.

Outras ações importantes, que desenvolvemos em sala de aula, estão relacionadas ao uso de ferramentas computacionais, das quais podemos citar o uso de softwares como uma 
metodologia potencial para ensinar matemática. Softwares como, por exemplo, GeoGebra, Graph, Wiplot, entre outros, onde propomos atividades orientadas, possibilitando ao aluno manipulações que permitem que ele possa realizar análises e comparações de diferentes situações dentro do conteúdo que está sendo desenvolvido e assim construir seu conhecimento. Um exemplo disso ocorre quando propomos atividades de análise de variação de parâmetros de funções, onde ao manipular diferentes gráficos o aluno poderá perceber as implicações dos coeficientes das variáveis em cada função. Nesta perspectiva, já apresentamos em trabalhos anteriores, como em [3], algumas discussões acerca do uso de softwares em aulas de matemática.

Dessa forma, como proposta de uso de tecnologias em sala de aula desenvolvemos uma oficina que foi elaborada com o objetivo de construir o conceito de derivada no ponto usando o software GeoGebra. Tal oficina foi estruturada contendo todos os passos que o aluno deverá seguir a fim de construir uma reta secante e uma reta tangente a uma determinada curva, considerando um ponto comum entre elas, onde a reta secante vinculada a um controle deslizante permite o movimento e a consequente aproximação à reta tangente apresentando assim a aproximação do coeficiente angular da reta secante ao coeficiente angular da reta tangente, ou seja, a derivada no ponto. Essa oficina foi desenvolvida em uma aula de Cálculo I, dos cursos de Engenharias. A estrutura da oficina consiste em duas atividades, a primeira apresenta uma orientação ao aluno considerando as ferramentas do GeoGebra na representação gráfica de uma curva, na construção de pontos sobre a curva, de retas secantes e de retas tangentes e a segunda propõe uma verificação da derivada no ponto através do seu cálculo manual.

Durante todo o desenvolvimento da oficina, foram propostas discussões e questionamentos, no sentido de desenvolver o raciocínio dedutivo acerca do conceito de derivada em um ponto levando o aluno a perceber através do GeoGebra, que as retas secantes se aproximam da reta tangente no ponto fixo e através do cálculo manual concluírem que os coeficientes angulares das retas secantes se aproximam do coeficiente angular da reta tangente, construindo assim o conceito de derivada em um ponto como limite dos coeficientes angulares das retas secantes ao gráfico da função por esse ponto.

Vale ressaltar que o aluno, motivado pelo uso do software mostra-se participativo e atuante atingindo o objetivo proposto inicialmente para esta oficina, ou seja, compreendendo o conceito de derivada no ponto com mais significado, fatos estes evidenciados na participação deste aluno nas aulas subsequentes.

A utilização de recursos computacionais como metodologia de ensino, está cada vez mais presente em nossa prática, pois percebemos que esta metodologia tem grande potencial para o ensino e aprendizagem em diferentes disciplinas, e também por entendemos que o uso de tecnologias não consiste apenas em um recurso a mais para os professores motivarem suas aulas; consiste em um meio influente que pode propiciar aos alunos novas formas de gerar e disseminar o conhecimento e, consequentemente, propiciar uma formação condizente com os anseios da sociedade.

Palavras-Chave: Matemática, Ensino Superior, Softwares.

\section{Referências}

[1] R. Araujo, R., L. F. N. Moreira, Monitoria da disciplina de Cálculo, em "Congresso Brasileiro de Ensino de Engenharia - XXXIII COBENGE”, Campina Grande, PB, 2005.

[2] H. N. Cury, Estilos de aprendizagem de alunos de engenharia, em "Congresso Brasileiro de Engenharia de Ensino de Engenharia - XXVIII COBENGE”, Ouro Preto, 2000.

[3] C. Piva, L. Dorneles, A. P. Spilimbergo, A. F. Dosciati, Articulação entre álgebra e geometria de sistemas lineares em ambiente informatizado: uma experiência em curso de engenharia, em "Congresso Internacional de Matemática, Engenharia e Sociedade - ICMES", Curitiba. PR: 2009. 